\title{
A psychometric appraisal of the DREEM
}

\author{
Sean M Hammond ${ }^{1 *}$, Margaret O'Rourke ${ }^{2}$, Martina Kelly ${ }^{2}$, Deirdre Bennett ${ }^{2}$ and Siun O'Flynn ${ }^{2}$
}

\begin{abstract}
Background: The quality of the Educational environment is a key determinant of a student centred curriculum. Evaluation of the educational environment is an important component of programme appraisal. In order to conduct such evaluation use of a comprehensive, valid and reliable instrument is essential. One of most widely used contemporary tools for evaluation of the learning environment is the Dundee Ready Education Environment Measure (DREEM). Apart from the initial psychometric evaluation of the DREEM, few published studies report its psychometric properties in detail. The aim of this study was to examine the psychometric quality of the DREEM measure in the context of medical education in Ireland and to explore the construct validity of the device.

Methods: 239 final year medical students were asked to complete the DREEM inventory. Anonymised responses were entered into a database. Data analysis was performed using PASW 18 and confirmatory factor analysis performed.

Results: Whilst the total DREEM score had an acceptable level of internal consistency (alpha 0.89), subscale analysis shows that two subscales had sub-optimal internal consistency. Multiple group confirmatory factor analysis (using Fleming's indices) shows an overall fit of 0.76, representing a weak but acceptable level of fit. 17 of the 50 items manifest fit indices less than 0.70 . We sought the best fitting oblique solution to the 5 -subscale structure, which showed large correlations, suggesting that the independence of the separate scales is open to question.

Conclusions: There has perhaps been an inadequate focus on establishing and maintaining the psychometric credentials of the DREEM. The present study highlights two concerns. Firstly, the internal consistency of the 5 scales is quite variable and, in our sample, appears rather low. Secondly, the construct validity is not well supported. We suggest that users of the DREEM will provide basic psychometric appraisal of the device in future published reports.
\end{abstract}

\section{Background}

In 1998, the World Federation for Medical Education highlighted the learning environment as one of the targets for the evaluation of medical education programmes [1]. It is widely agreed among medical educators that the effects of the educational environment, both academic and clinical, are important determinants of medical students attitudes, knowledge, skills, progression and behaviours [2,3]. Evaluation of the educational environment at both academic and clinical sites is key to the delivery of a high quality, student centred curriculum [4]. In order to conduct such evaluation across many sites, specialties and student groups use of a comprehensive, valid and reliable instrument is essential.

\footnotetext{
* Correspondence: s.hammond@ucc.ie

'School of Applied Psychology, University College Cork, College road, Cork, Ireland

Full list of author information is available at the end of the article
}

Over the last 4 decades educators and researchers have attempted to define and measure the medical education environment [5-11] and the most widely used contemporary development is almost certainly the Dundee Ready Education Environment Measure (DREEM) [12]. The DREEM is a 50-item measure of students' perceptions of their learning environment resulting in scores on five scales. These are labeled, perception of learning, perception of course organizers, academic self perception, perception of atmosphere and social self perception.

The DREEM has proved itself internationally useful in a variety of healthcare settings [13], such as medical, dental, nursing and chiropractic learning environments [14-17]. It has been used to identify weaknesses in curricula with a view to introducing change [18-21], and has been applied to assess the impact of new curricular interventions $[22,23,16]$. Its focus on student experience has led to its
C Biomed Central

(ㄷ) 2012 Hammond et al; licensee BioMed Central Ltd. This is an Open Access article distributed under the terms of the Creative Commons Attribution License (http://creativecommons.org/licenses/by/2.0), which permits unrestricted use, distribution, and reproduction in any medium, provided the original work is properly cited. 
use in identifying the gap between student expectations and experience [24] and student actual and idealised experience [20]. Furthermore, differences between student experience at different sites within medical schools $[25,26]$ and between students perceptions at different stages of their medical education [22], have also been examined using the DREEM. One important use of the DREEM has been as a utility for international comparisons between medical schools $[27,28]$. This has allowed medical schools to benchmark the educational environment they are providing $[29,30]$.

Its developers have provided a simple guide to interpreting the scores derived from the DREEM making it an accessible and easy-to-use device for evaluating the learning environment in medical education settings [31]. Nevertheless, the fact that it is very commonly used for cross-national comparisons makes it particularly important that it is subject to close ongoing psychometric scrutiny to protect against cultural bias. If the psychometric properties of a device fluctuate across countries, conclusions based on the scale may actually reflect artifacts due to unreliability and lack of validity. There have been repeated calls for rigorous evaluation of the psychometric properties of measures used cross-nationally [32-34], but they are not commonly applied in educational climate studies.

Apart from the initial psychometric evaluation of the DREEM carried out by its originators [12], few of the published studies report it's psychometric properties in any detail. Two exceptions include studies in Portugal, Greece and Sweden $[28,29,35]$. Results were mixed showing variable levels of internal consistency for the 5 subscales. In addition, factor analyses did not support the 5 -factor structure claimed by the DREEM developers. Both studies concluded that the DREEM had clear value and generalized well across different programs but the psychometric shortcomings exposed by their study do invite further scrutiny.

The present study had the following objectives:

1. To examine the psychometric quality of the DREEM measure in the context of medical education in Ireland.

2. To explore the construct validity of the device.

\section{Method \\ Participants}

Two cohorts of medical students in their final year of study at University College Cork were sampled. Cohort 1 comprised those entering their final year in 2007 and cohort 2 comprised those entering in 2008. In addition, a third cohort of graduate entry students was sampled for comparison. The complete sample consisted of 239 students.

\section{Materials/Instruments Used}

Each participant completed the DREEM along with other self-report measures which were part of a larger stress audit study [36]. The focus of this paper is on the DREEM and it was noted that participants took between five and seven minutes to complete this measure.

\section{Procedure}

Before proceeding, ethical approval was granted by the Clinical Research Ethics Committee of the Cork Teaching Hospitals.

Each participant in the present study was asked to complete the DREEM which was presented as part of a test battery. The task of completing the DREEM was presented during a timetabled lecture slot where the determinants of self directed learning were explored and consequently this material was relevant and although participants were free to withdraw there was 100\% adherence.

\section{Data Management/Analyses}

The completed questionnaire responses were entered into an anonymised database for subsequent analysis. Data analysis was performed using PASW 18 and the confirmatory factor analysis was performed using a customised programme written for a windows platform, by the first author.

\section{Results}

Of the 239 medical students participating in this study, 151 were female and 87 were male (one person did not register their gender). Ages ranged between 17 and 39 with a median of 22. The first cohort comprised final year medical students collected in $2007(\mathrm{~N}=102)$ the second comprised final year medical students collected in $2008(\mathrm{~N}=99)$ and the third comprised $1^{\text {st }}$ year Graduate entry medical students collected in 2008 ( $n=37)$.

The basic psychometric properties of the DREEM in our sample are reported in table 1 . The means and standard deviations appear well within the expected range of scores. Using the guide to interpreting subscale scores [31], it may be concluded that Cork medical students are relatively positive about all aspects of the course. Only two of the scales (Perception of Learning and Academic Self-perception) manifest an alpha exceeding the widely

Table 1 Classical Psychometric Properties

\begin{tabular}{lcccc}
\hline Subscale & Mean & S.D. & $\mathbf{n}$ & $\boldsymbol{\alpha}$ \\
\hline Learning & 30.59 & 6.38 & 12 & 0.78 \\
Course Organisers & 29.28 & 5.34 & 11 & 0.69 \\
Academic Self Perception & 18.57 & 4.98 & 8 & 0.74 \\
Atmosphere & 31.33 & 6.02 & 12 & 0.56 \\
Social Self-Perception & 17.55 & 3.95 & 7 & 0.55 \\
\hline Total Score & 127.08 & 21.02 & 50 & 0.89 \\
\hline
\end{tabular}


adopted rule of thumb guide of 0.70 [37]. The total DREEM score, in contrast, appears to manifest an acceptable level of internal consistency.

The fact that the subscales lack convincing internal consistency raises concerns about the construct validity of the DREEM. In order to evaluate the putative subscale structure of the questionnaire a multiple group confirmatory factor analysis $[38,39]$, was carried out using the DREEM scoring key as an hypothesis matrix. The results are presented in table 2 . In a perfect fit to the proposed 5 -factor model each DREEM item will load on only one factor producing a value of unity with loadings on all other factors manifesting as zero. In reality such perfect solutions never arise so, in order to evaluate the degree

Table 2 Factor Pattern following a Confirmatory Multiple Group Factor Analysis

\begin{tabular}{|c|c|c|c|c|c|c|}
\hline \multirow[t]{2}{*}{ ITEM } & \multicolumn{6}{|c|}{ FACTORS } \\
\hline & I & II & III & IV & V & $\begin{array}{l}\text { Item } \\
\text { Fit }\end{array}$ \\
\hline Q1 & 0.280 & -0.002 & -0.034 & 0.112 & -0.091 & 0.780 \\
\hline Q7 & 0.328 & 0.022 & 0.005 & -0.008 & 0.021 & 0.991 \\
\hline Q13 & 0.343 & 0.043 & -0.092 & -0.076 & 0.057 & 0.860 \\
\hline Q16 & 0.398 & -0.234 & 0.006 & -0.021 & 0.099 & 0.708 \\
\hline Q20 & 0.386 & -0.032 & 0.024 & -0.160 & 0.123 & 0.778 \\
\hline Q21 & 0.369 & -0.128 & 0.010 & 0.092 & -0.090 & 0.804 \\
\hline Q24 & 0.337 & -0.044 & -0.031 & 0.075 & -0.015 & 0.928 \\
\hline Q25 & 0.140 & 0.179 & -0.056 & -0.043 & 0.015 & 0.347 \\
\hline Q38 & 0.253 & 0.012 & 0.092 & -0.018 & -0.083 & 0.803 \\
\hline Q44 & 0.267 & -0.083 & 0.076 & 0.079 & -0.013 & 0.790 \\
\hline Q47 & 0.087 & 0.148 & 0.090 & 0.014 & 0.064 & 0.180 \\
\hline Q48 & 0.207 & 0.119 & -0.089 & -0.047 & -0.087 & 0.574 \\
\hline $\mathrm{Q} 2$ & 0.119 & 0.268 & -0.063 & 0.051 & 0.013 & 0.774 \\
\hline Q6 & 0.077 & 0.238 & 0.046 & 0.051 & -0.078 & 0.772 \\
\hline Q8 & -0.115 & 0.450 & -0.103 & -0.039 & -0.130 & 0.828 \\
\hline Q9 & -0.202 & 0.516 & 0.016 & -0.072 & -0.057 & 0.843 \\
\hline Q18 & 0.093 & 0.302 & -0.013 & -0.075 & 0.019 & 0.860 \\
\hline Q29 & -0.057 & 0.326 & 0.062 & -0.011 & 0.046 & 0.920 \\
\hline Q32 & 0.121 & 0.186 & -0.019 & 0.037 & -0.020 & 0.672 \\
\hline Q37 & 0.055 & 0.229 & 0.106 & -0.034 & 0.094 & 0.684 \\
\hline Q39 & -0.122 & 0.407 & 0.021 & -0.084 & -0.053 & 0.868 \\
\hline Q40 & 0.166 & 0.292 & -0.132 & -0.020 & 0.062 & 0.635 \\
\hline Q49 & -0.134 & 0.141 & 0.079 & 0.197 & 0.104 & 0.212 \\
\hline Q5 & -0.079 & -0.003 & 0.348 & -0.008 & 0.111 & 0.866 \\
\hline Q10 & -0.029 & -0.036 & 0.415 & -0.010 & -0.058 & 0.969 \\
\hline Q22 & 0.135 & -0.119 & 0.264 & 0.125 & -0.107 & 0.539 \\
\hline Q26 & -0.034 & -0.055 & 0.464 & -0.028 & -0.081 & 0.949 \\
\hline Q27 & -0.091 & -0.075 & 0.417 & -0.031 & 0.044 & 0.911 \\
\hline Q31 & -0.019 & 0.134 & 0.293 & -0.014 & 0.020 & 0.819 \\
\hline Q41 & 0.024 & 0.071 & 0.272 & 0.036 & 0.039 & 0.898 \\
\hline Q45 & 0.092 & 0.084 & 0.284 & -0.070 & 0.031 & 0.791 \\
\hline Q11 & -0.053 & 0.025 & 0.029 & 0.322 & -0.050 & 0.938 \\
\hline Q12 & 0.084 & 0.114 & -0.128 & 0.226 & -0.061 & 0.561 \\
\hline Q17 & -0.310 & 0.074 & 0.066 & 0.247 & -0.033 & 0.363 \\
\hline
\end{tabular}

Table 2 Factor Pattern following a Confirmatory Multiple Group Factor Analysis (Continued)

\begin{tabular}{lcccccc}
\hline Q23 & -0.016 & 0.101 & 0.189 & 0.109 & -0.002 & 0.203 \\
Q30 & 0.163 & 0.046 & -0.051 & 0.212 & -0.074 & 0.551 \\
Q33 & -0.039 & -0.046 & -0.026 & 0.408 & -0.009 & 0.974 \\
Q34 & -0.071 & 0.003 & -0.138 & $\mathbf{0 . 4 6 5}$ & 0.036 & 0.895 \\
Q35 & 0.033 & -0.243 & -0.099 & $\mathbf{0 . 3 2 6}$ & 0.127 & 0.553 \\
Q36 & 0.061 & -0.119 & 0.101 & $\mathbf{0 . 1 6 3}$ & 0.098 & 0.412 \\
Q42 & 0.056 & -0.044 & -0.002 & $\mathbf{0 . 2 4 1}$ & 0.077 & 0.841 \\
Q43 & 0.102 & -0.014 & 0.134 & $\mathbf{0 . 1 3 1}$ & 0.039 & 0.362 \\
Q50 & -0.009 & 0.103 & -0.076 & $\mathbf{0 . 2 0 4}$ & -0.147 & 0.521 \\
Q3 & 0.080 & 0.009 & -0.008 & 0.016 & $\mathbf{0 . 2 4 1}$ & 0.895 \\
Q4 & -0.113 & -0.281 & 0.136 & -0.001 & $\mathbf{0 . 3 7 4}$ & 0.559 \\
Q14 & 0.018 & 0.038 & -0.034 & 0.019 & $\mathbf{0 . 3 9 5}$ & 0.979 \\
Q15 & 0.142 & -0.003 & -0.138 & -0.070 & $\mathbf{0 . 4 3 3}$ & 0.809 \\
Q19 & -0.152 & 0.031 & 0.147 & 0.002 & $\mathbf{0 . 4 0 5}$ & 0.782 \\
Q28 & -0.023 & 0.043 & -0.066 & 0.002 & $\mathbf{0 . 4 4 4}$ & 0.967 \\
Q46 & 0.047 & 0.163 & -0.038 & 0.033 & $\mathbf{0 . 2 1 1}$ & 0.587 \\
\hline Factor & 0.712 & 0.726 & 0.773 & 0.845 & 0.807 & 0.765 \\
Fit & & & & & & \\
\hline
\end{tabular}

of fit to the model, indices of fit are used. In this study, Fleming's index is used [40]. This shows the fit for each item (seen in the last column of table 2) and also the degree to which each factor fits the model (seen in the last column). The overall fit is estimated as 0.76 . As a signal to noise ratio, Fleming's indices share the logic of Cronbach's alpha and may be interpreted similarly. Therefore, an index of 0.76 represents a weak but acceptable level of fit. Nevertheless, bearing in mind the procrustean basis of the multiple group factor analysis procedure, a higher degree of fit would be expected if the model in question was robust and reliable.

It is found that 17 of the 50 items manifest fit indices less than 0.70 .

The current analysis sought the best fitting oblique solution to the 5 -subscale structure. As such it provides correlations between the factors and these are reported in table 3 . These correlations are very large suggesting that the independence of the separate scales is open to question.

\section{Discussion}

The DREEM is undoubtedly a useful tool for appraising the educational climate in medical education and its

Table 3 Factor Correlation Matrix

\begin{tabular}{lccccc}
\hline & I & II & III & IV & V \\
\hline I. Perception of teaching: & 1.000 & & & & \\
II. Perception of teachers & 0.821 & 1.000 & & & \\
III. Academic self-perception & 0.788 & 0.767 & 1.000 & & \\
IV. Atmosphere & 0.842 & 0.768 & 0.824 & 1.000 & \\
V. Social self-perception & 0.738 & 0.653 & 0.737 & 0.743 & 1.000 \\
\hline
\end{tabular}


widespread international use reveals the need for such a device. However, there has perhaps been an inadequate focus on establishing and maintaining it's psychometric credentials. The present study highlights two concerns that may need attention. Firstly, the internal consistency of the 5 scales is quite variable and, in this sample, appears rather low. Secondly, the construct validity (the basis for the 5 subscales) is not well supported. Both of these findings do appear to be consistent with the Portugese [28], Greek [29] and Swedish [35] studies cited above. Given that our findings are based on Irish medical students it is unlikely that these weaknesses can be attributed to translation factors. As a result it is clear that the putative 5 -factor model proposed by the developers of the DREEM is not supported and may be in need of revision.

It may also be tempting to suggest that a shortened 33 item DREEM may be formed by jettisoning the 17 weakest items identified in our factor analysis. However, great care needs to be taken in adopting such a strategy. Firstly, the weakest items in an Irish sample may not be the same as those identified in another nationality and secondly, in removing items the underlying factor structure may change dramatically. In the Roff et al. paper [12] describing the development of the DREEM it is clear that the subscale structure was driven by a-priori theoretical reasoning. The fact that empirical data do not conform well with this model might suggest that either the items need to be reframed to fit the model or that the model itself needs to be reconsidered. There is not yet sufficient published psychometric analysis across nationalities on the DREEM to suggest which is the most beneficial route to take in this regard.

Indeed, our finding showing very high correlations between the subscale factors may support the contention that the DREEM is essentially a one-factor single scale instrument. There is very little discrimination evident between the 5 subscales and reports of the DREEM do not typically examine the differential validity of the subscales.

\section{Conclusion}

DREEM enjoys widespread usage as an instrument which measures the educational environment however factor analysis and subscale factor analysis raise questions about its basic psychometric properties and construct validity. These issues need to be addressed if DREEM continues to be used. Certainly, the latent model upon which it is built may need to be radically revised. This may be best achieved by a full integration of the existing multinational exploratory analyses of the DREEM structure to inform a new empirically based latent model. This might then be followed by a large scale international sample being subjected to a full Structural Equation Modelling analysis. It is hoped that users of the DREEM will provide basic psychometric appraisal of the device in future published reports so that a more generalized picture of its cross-national viability becomes available.

\section{Author details}

${ }^{1}$ School of Applied Psychology, University College Cork, College road, Cork, Ireland. ${ }^{2}$ School of Medicine, University College Cork, College road, Cork, Ireland.

\section{Authors' contributions}

SM drafted the manuscript, participated in design of the study and carried out the analysis. MO'R participated in design and coordination was also responsible for data collection. MK participated in the design of the study. DB participated in the design of the study. SO'F conceived the study and participated in the design and coordination. All authors read, revised and approved the final manuscript.

\section{Competing interests}

The authors declare that they have no competing interests.

Received: 2 May 2011 Accepted: 12 January 2012

Published: 12 January 2012

\section{References}

1. The Executive Council WFME: International standards in medical education: assessment and accreditation of medical schools' educational programmes. A WFME position paper. Medical Education 1998, 32(5):549-558.

2. Genn JM: Curriculum, environment, climate quality and change in medical education - a unifying perspective. Medical Teacher 2001, 23(5):445-454

3. Roff S, Mcaleer S: What is educational climate? Medical Teacher 2001, 23(4):333-34.

4. Harden RM: The learning environment and the curriculum. Medical Teacher 2001, 23(4):335-336.

5. Rothman Al, Ayoade F: The development of a learning environment: a questionnaire for use in curriculum evaluation. Journal of Medical Education 1970, 45:754-759.

6. Marshall RE: Measuring the medical school learning environment. Journal of Medical Education 1978, 53:98-104.

7. Feletti Gl, Clarke RM: Review of psychometric features of the medical school learning environment survey. Medical Education 1981, 15:92-96.

8. Moore-west M, Harrington DL, Mennin SP, Kaufman A, Skipper BJ: Distress and attitudes toward the learning environment: effects of a curriculum innovation. Teaching and Learning in Medicine 1989, 1:151-157.

9. General medical council: Tomorrow's Doctors. Recommendations on Undergraduate Medical Education London, General Medical Council; 1993.

10. Chan DSK: Combining qualitative and quantitative methods in assessing hospital learning environments. International Journal of Nursing Studies 2001, 38:447-459.

11. Mulrooney A: Development of an instrument to measure the Practice Vocational Training Environment in Ireland. Medical Teacher 2005, 27(4):338-342.

12. Roff S, Mcaleer S, Harden RM, Al-qahtani M, Ahmed AU, Deza H, Groenen G, Primparyon P: Development and validation of the Dundee Ready Education Environment Measure (DREEM). Medical Teacher 1997, 19:295-299.

13. Roff S: The Dundee Ready Educational Environment Measure (DREEM)-a generic instrument for measuring students' perceptions of undergraduate health professions curricula. Medical Teacher 2005, 27:322-325.

14. Said NM, Rogayah J, Hafizah A: A Study of Learning Environments in the Kulliyyah (Faculty) of Nursing, International Islamic University Malaysia. Malaysian Journal of Medical Sciences 2009, 16:11-20.

15. Thomas BS, Abraham RR, Alexander M, Ramnarayan K: Students' perceptions regarding educational environment in an Indian dental school. Medical Teacher 2009, 31:185-188.

16. Till $\mathrm{H}$ : Identifying the perceived weaknesses of a new curriculum by means of the Dundee Ready Education Environment Measure (DREEM) Inventory. Medical Teacher 2004, 26:39-45. 
17. Soemantri D, Herrera C, Riquelme A: Measuring the educational environment in health professions studies: A systematic review. Medical Teacher 2010, 32:947-952

18. Al-hazimi A, Al-hyiani A, Roff S: Perceptions of the educational environment of the medical school in king Abdul Aziz university, Saudi Arabia. Medical Teacher 2004, 26:570-573.

19. Till H: Climate studies: can students' perceptions of the ideal educational environment be of use for institutional planning and resource utilization? Medical Teacher 2005, 27:332-337.

20. Bouhaimed M, Thalib L, Doi SAR: Perception of the Educational Environment by Medical Students Undergoing a Curricular Transition in Kuwait. Medical Principles, Practice 2009, 18:204-208.

21. Shehnaz SI, Sreedharan J: Students' perceptions of educational environment in a medical school experiencing curricular transition in United Arab Emirates. Med Teach 2011, 33(1):e37-42.

22. Demirören M, Palaoglu Ö, Kemahli S, Özyurda F, Ayhan IH: Perceptions of Students in Different Phases of Medical Education of Educational Environment: Ankara University Faculty of Medicine. Medical Education Online 2008, 13:1-8.

23. Edgren G, Haffling A-C, Jakobsson U, Mcaleer S, Danielsen N: Comparing the educational environment (as measured by DREEM) at two different stages of curriculum reform. Medical Teacher 2010, 32:e233-e238.

24. Miles S, Leinster SJ: Medical students' perceptions of their educational environment: expected versus actual perceptions. Medical Education 2007, 41:265-272.

25. Carmody DF, Jacques A, Denz-penhey H, Puddey I, Newnham JP: Perceptions by medical students of their educational environment for obstetrics and gynaecology in metropolitan and rural teaching sites. Medical Teacher 2009, 31:e596-e602.

26. Bennett D, Kelly M, O'flynn S: Are the bigger hospitals better: DREEM on? Irish Journal of Medical Science 2010, 1-5.

27. Roff S, Mcaleer S, Ifere OS, Bhattacharya S: A global diagnostic tool for measuring educational environment: comparing Nigeria and Nepal. Medical Teacher 2001, 23:378-382.

28. Rodrigues de oliveira filho GR, Viera JE, Schonhorst L: Problem-based learning implementation in an intensive course of anaesthesiology: a preliminary report on residents' cognitive performance and perceptions of the educational environment. Medical Teacher 2005, 27(4):382-384.

29. Dimoliatis IDK, Vasilaki E, Anastassopoulos P, loannidis JPA, Roff S: Validation of the Greek Translation of the Dundee Ready Education Environment Measure (DREEM). Education for Health 2010, 23(1), (Online) Available from: http://www.educationforhealth.net.

30. Aghamolaei T, Fazel I: Medical students' perceptions of the educational environment at an Iranian Medical Sciences University. BMC Medical Education 2010, 10:87.

31. Mcaleer S, Roff S: Part 3; A practical guide to using the Dundee Ready Education Measure (DREEM). In AMEE Medical Education Guide No.23 Curriculum, environment, climate, quality and change in medical education; a unifying perspective. Edited by: Genn JM. Dundee, UK: Association of Medical Education in Europe; 2002:

32. De beuckelaer A, Swinne G: Biased Latent Variable Mean Comparisons due to Measurement Noninvariance: A Simulation Study. In Cross-cultural analysis: Methods and Applications. Edited by: Davidov E, Schmitt P, Billiet J. Routledge, New York; 2011:117-148.

33. De beuckelaer A, Swinne G: Biased Latent Variable Mean Comparisons due to Measurement Noninvariance: A Simulation Study. In Cross-cultural analysis: Methods and Applications. Edited by: Davidov E, Schmitt P, Billiet J. Routledge, New York; 2011:117-148.

34. Van de vjver V, Leung K: Methods and Data Analysis for Cross-Cultural Research. Sage Publications; 1997.

35. Jakobsson U, Danielsen N, Edgren G: Psychometric evaluation of the Dundee Ready Educational Environment Measure: Swedish version. Med Teach 2011, 33(5):e267-274.

36. O'rourke M, Hammond S, O'flynn S, Boylan G: The Medical Student Stress Profile: a tool for stress audit in medical training'. Medical Education 2010, 44(10):1027-1037.

37. Nunnaly JC: Psychometric theory New York: McGraw-Hill; 1978.

38. Levin J: Multiple Group Factor Analysis of Multitrait-Multimethod Matrices. Multivariate Behavioral Research 1988, 23(4):469.
39. Everett JE, Entrekin LV: Factor comparability and the advantages of multiple group factor analysis. Multivariate Behavioral Research 1980, 15(2):165

40. Flemming : An Index of Fit for Factor Scales. Educational and Psychological Measurement 1985, 45(4):725-728.

\section{Pre-publication history}

The pre-publication history for this paper can be accessed here: http://www.biomedcentral.com/1472-6920/12/2/prepub

doi:10.1186/1472-6920-12-2

Cite this article as: Hammond et al:: A psychometric appraisal of the DREEM. BMC Medical Education 2012 12:2.

\section{Submit your next manuscript to BioMed Central and take full advantage of:}

- Convenient online submission

- Thorough peer review

- No space constraints or color figure charges

- Immediate publication on acceptance

- Inclusion in PubMed, CAS, Scopus and Google Scholar

- Research which is freely available for redistribution

Submit your manuscript at www.biomedcentral.com/submit
C) Biomed Central 